\title{
Correlation between indoor air pollution and adult respiratory health in Zunyi City in Southwest China: situation in two different seasons
}

Shixu Li, Jie Xu, Zhigang Jiang, Ya Luo, Yu Yang and Jie Yu (D)

\begin{abstract}
Background: Indoor environmental quality significantly influences the occurrence of asthma attack. Zunyi District has abundant coal reserves and is regarded as one of the cities that are most severely polluted by high levels of particulate matter in China. This study aimed to examine the correlation of indoor exposure with adult respiratory health, as well as the differences in effect between winter and summer.

Methods: A cross-sectional epidemiological study was conducted among 1207 adult residents in Zunyi, Guizhou Province of Southwest China in winter and summer. Data on health variables related to asthma and home environmental factors were collected using a modified European Community Respiratory Health Survey II questionnaire. The following data were obtained: samples of particulate matter $2.5\left(\mathrm{PM}_{2.5}\right)$ inside and outside the households under study $(n=20)$; lung function status, including peak expiratory flow rate, forced vital capacity (FVC), forced expiratory volume in $1 \mathrm{~s}\left(\mathrm{FEV}_{1}\right)$, and $\mathrm{FEV}_{1} / \mathrm{FVC}$ ratio.

Result: The odds ratio (OR) for asthma-like symptoms and asthma in adults using coal stove for cooking or warming, relative to non-users, was $1.73(95 \% \mathrm{Cl}, 1.11-2.69)$ in winter vs. 1.30 (95\% Cl, 0.79-2.14) in summer. Adult residents with exposure to cooking oil fumes were at a considerably higher risk of asthma-like symptoms and asthma [OR $=2.65(95 \% \mathrm{Cl}, 1.25$ to 5.61$)$ in winter vs. $\mathrm{OR}=7.93(95 \% \mathrm{Cl}, 2.54$ to 24.75$]$ in summer] than those without such exposure. The prevalence of asthma-like symptoms and asthma was significantly higher in adults with high kitchen risk scores or high sleeping-area risk scores than in those with low scores in both seasons $(p<0.05)$. The relative kitchen and sleeping area $\mathrm{PM}_{2.5}$ concentrations were higher in winter than in summer $(p<0.05)$. Lung function was negatively associated with indoor kitchen and sleeping area relative $\mathrm{PM}_{2.5}$ concentration in winter rather than summer $(p<0.001)$. The effect of exposure to indoor risk factors on lung function among the residents was greater in winter than in summer $(p<0.001)$.

Conclusion: Exposure to indoor risk factors, such as aerocontaminants from coal combustion, causes asthma symptoms and reduces pulmonary function. The effect of indoor risk factors on respiratory health among adults with such exposure was greater in winter than in summer.
\end{abstract}

Keywords: Asthma, Asthma-related symptoms, Adult, Indoor, Season

\footnotetext{
* Correspondence: Xujie360@hotmail.com

School of Public Health, Zunyi Medical University, Zunyi, Guizhou 563000

People's Republic of China

(c) The Author(s). 2019 Open Access This article is distributed under the terms of the Creative Commons Attribution 4.0 International License (http://creativecommons.org/licenses/by/4.0/), which permits unrestricted use, distribution, and reproduction in any medium, provided you give appropriate credit to the original author(s) and the source, provide a link to the Creative Commons license, and indicate if changes were made. The Creative Commons Public Domain Dedication waiver (http://creativecommons.org/publicdomain/zero/1.0/) applies to the data made available in this article, unless otherwise stated.
} 


\section{Background}

Indoor air pollution (IAP) is considered one of the major human health concerns in modern society as people spend approximately $90 \%$ of their time indoors, particularly at their own homes. Three billion people worldwide are exposed daily to aerocontaminants of IAP owing to the use of solid fuels such as coal or biomass fuels for combustion. Such use leads to the release of products of incomplete combustion (i.e., particulate matter $\left.2.5\left(\mathrm{PM}_{2.5}\right)\right)$ [1].

An increasing number of studies have indicated that indoor air pollution, as well as lifestyle, contributes to the high prevalence rate of asthma and deterioration of pulmonary function [2-4]. Recent epidemiologic studies showed that asthma-like symptoms and asthma among adult residents in Zunyi have a prevalence of $13.1 \%$ in winter [2]. Chronic lung diseases and respiratory tract cancers are strongly associated with pollution from coal burning and other solid fuels [3]. In Europe and North America, studies have demonstrated that even shortterm changes in indoor air pollution, other than meteorological conditions, can increase respiratory morbidity in winter or in summer [4,5]. Several studies have been conducted on indoor risk factor and pulmonary health worldwide [6, 7]. However, comparative studies on the respiratory health effects of indoor air pollution in summer and winter have rarely been reported.

The rapid increase in asthma in recent years cannot be attributed to changes in genetic factor, interventions for the increased prevalence of asthma should be focused on environmental factors. Evidence strongly suggests that exposure to indoor risk factors, including fuel combustion, environmental tobacco smoke, and allergens, can significantly trigger and exacerbate asthma morbidity among adults [8]. Indoor particulate matter affects lung function development, aggravates asthma, and causes other respiratory symptoms [9]. Zunyi has a large coal reserve with high levels of indoor air pollution, The correlation between indoor exposure and adult respiratory health, as well the disparities in effect between winter and summer, prompts interest.

\section{Methods}

\section{Study design and population}

Adult residents in Zunyi, Guizhou Province in Southwest China were sampled in summer $(n=610$ from June to August 2012) and in winter $(n=1207$ from December 2011 to February 2012). Recruitment of the population in this cross-sectional epidemiological study was conducted as described in our previous study [9]. The target group was recruited from 11 downtown areas in Zunyi by multistage cluster sampling. Owing to the relative socioeconomic homogeneity in these areas, one of these areas was randomly sampled in the first stage. Moreover, two of the selected downtown areas, which consisted of 10 residential communities, were randomly sampled in the second stage. The first recruited family in each community was ultimately randomly sampled by residential address. All adults living in the household were asked whether they would agree to participate in the study, and those who agreed were included. Next-door neighbors meeting these inclusion criteria were recruited as well. This procedure was repeated for each house in the selected clusters until the predefined number of residents was reached [10]. A total of 1207 adult residents from 517 households were recruited in winter, and 610 adults from 213 households participated in this study. Among the 1207 residents recruited in winter, 597 could not be traced in summer; meanwhile, the remaining 610 (51.0\%) residents participated in the summer survey. The non-traceability of some of the residents was attributed to the transformation of shanty towns, relocation, and refusal, among others. The inclusion criteria for eligible residents were as follows: female or male, age $>18$ years, and residence $>3$ years in Zunyi City. The exclusion criterion was history of asthma with concomitant diagnoses of chronic obstructive pulmonary disease (chronic bronchitis or emphysema) [2]. A flowchart is presented in Fig. 1.

\section{Sampling methods \\ Sample size}

To determine the sample size of the study, the formulas described by Fleiss, J.L. (1981), which are applicable for cross-sectional studies, were used [11]. With multistage cluster sampling design considered, the design effect on the prevalence of asthma and asthma-related symptoms was estimated to be 2, according to another survey [12]. Ultimately, the total sample size was 1086 . The actual survey sample consisted of 1207 adult residents recruited in winter and 610 adult residents recruited in summer.

\section{Research tools}

The cross-sectional epidemiological study included a questionnaire, spirometric examination, and monitoring of particulate matter $\left(\mathrm{PM}_{2.5}\right)$ pollution. The European Community Respiratory Health Survey II (ECRHS II), a self-administered modified questionnaire, was used to collect data on health variables that typically influence asthma-related symptoms, as well as personal and home environment factors.

The $\mathrm{PM}_{2.5}$ concentrations inside (the kitchen and bedroom) and outside the study households while cooking were measured using a real-time digital dust monitor (LD-3 K; Sibata Scientific Technology Inc., Japan) [9]. Air was sampled at a height of $1.2-1.5 \mathrm{~m}$ in each household. Within each household, three sites were sampled 


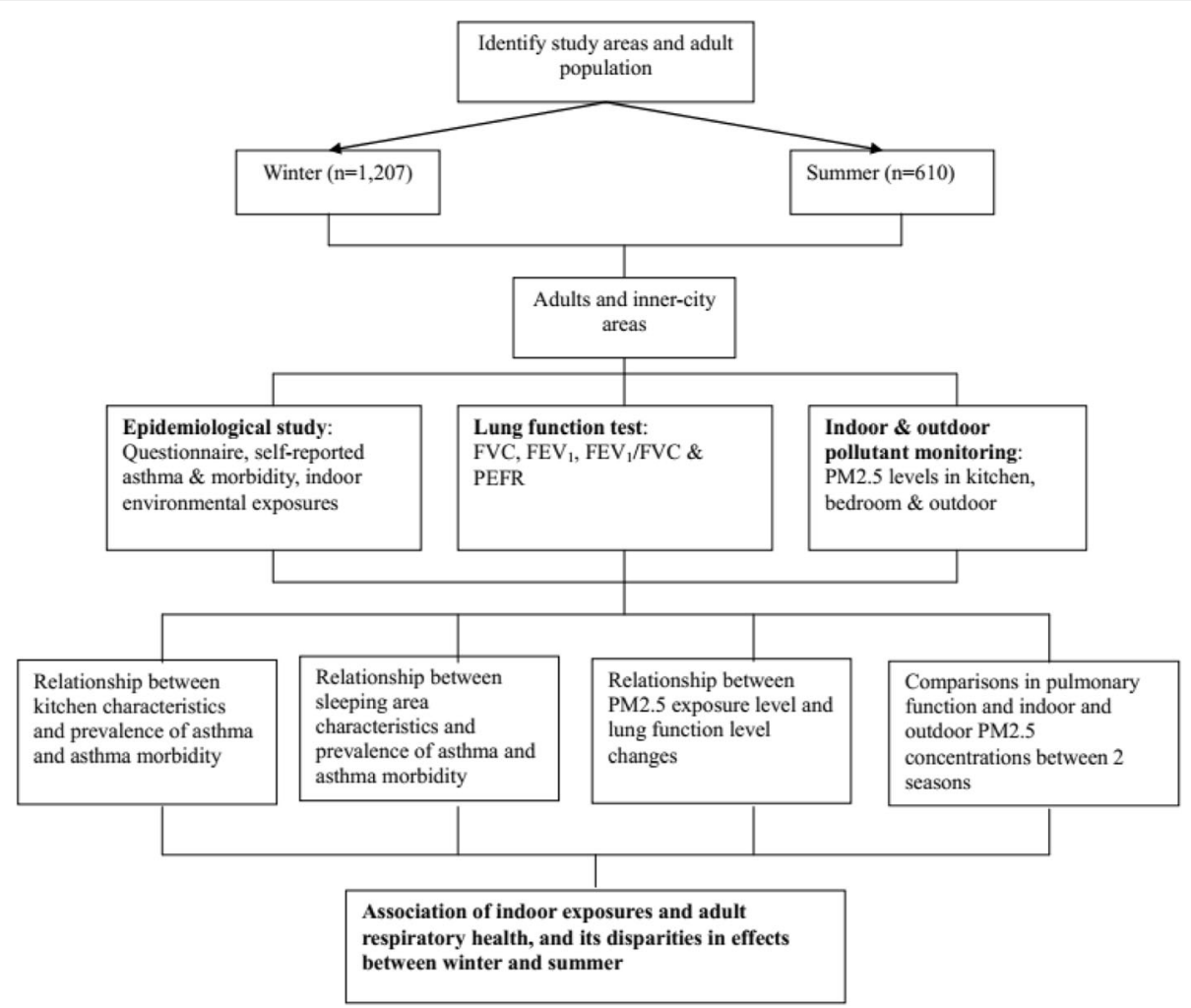

Fig. 1 Research flowchart

at $1 \mathrm{~m}$ from the cooking stove center. Three sites in the bedroom were randomly sampled at least $3 \mathrm{~m}$ away from the kitchen. Three outdoor positions $20 \mathrm{~m}$ away from the household were randomly sampled outside the study household as environmental control samples. The average of the three indoor and outdoor samples was determined. Each measurement was maintained for more than one minute, and three readings were utilized to calculate the average relative $\mathrm{PM}_{2.5}$ concentration. Monitoring was consistently applied across all households in summer and winter. To determine the relative $\mathrm{PM}_{2.5}$ concentration, 11 houses were selected from each residential community by simple random sampling, and 22 houses were selected for measurement in winter. In summer, two houses were not traceable, which was attributed to migration to other areas, leaving only 20 houses for measurement. Indoor and outdoor exposure levels to $\mathrm{PM}_{2.5}$ in the 20 houses were measured in winter and summer, and the results were compared.

Data on lung function status, including forced expiratory volume in $1 \mathrm{~s}\left(\mathrm{FEV}_{1}\right)$, forced vital capacity (FVC), peak expiratory flow rate (PEFR), and $\mathrm{FEV}_{1} / \mathrm{FVC}$ ratio in the household were determined using a portable electronic FGC-A ${ }^{+}$spirometer (Anhui Institute of Electronic Science, China) as described in our previous study [9]. The subjects, with feet on the ground and in an upright position, were asked to inhale completely and then exhale forcefully after the meter was put inside their mouths until the lips were sealed around the mouthpiece. This maneuver was demonstrated by an investigator. The maneuvers were only accepted when both FVC and $\mathrm{FEV}_{1}$ were within $0.20 \mathrm{~L}$ of the best-effort $\mathrm{FVC}$ and $\mathrm{FEV}_{1}$, back-extrapolated volumes were low $(<5 \%$ of the FVC and $<0.15 \mathrm{~L}$ ), and the final accumulated volume was low in accordance with the practice guideline of the American Thoracic Society. Three expiratory maneuvers were conducted for each subject. The largest FVC of the two curves, the ratio of the largest $\mathrm{FEV}_{1}$ to the largest $\mathrm{FVC}$, the largest $\mathrm{FEV}_{1}$, and the largest PEFR were analyzed [9].

\section{Assignment of scores for potential source of indoor exposure in winter and summer}

In this study, 20 potential sources of indoor exposure (19 in summer) concerning kitchen and sleeping area characteristics were identified. Each source of indoor exposure was assigned an exposure score. In summer, the sums of maximum and minimum kitchen risk exposure scores were 22 and 0 , respectively, and the sums of sleeping-area risk exposure scores were 19 and 0 , respectively. In winter, the sums of maximum and minimum kitchen risk exposure scores were 27 and 0 , 
respectively. Similarly, the sum of the maximum and minimum sleeping-area exposure scores were 23 and 0 , respectively. Winter and summer questionnaires, together with instructions for the questionnaire and exposure score, are indicated in Additional files 1, 2, 3.

\section{Data analysis}

The results were statistically analyzed using SPSS version 20.0. The types of distribution-that is, whether they are normal distributions-were ascertained. Wilcoxon signed-rank test was used for paired comparison between the pulmonary function $\left(\mathrm{FVC}, \mathrm{FEV}_{1}, \mathrm{FEV}_{1} / \mathrm{FVC}\right.$, and PEFR) of adults in winter and in summer. Meanwhile, the Mann-Whitney $U$ test was used for comparison between indoor and outdoor relative $\mathrm{PM}_{2.5}$ concentrations. Logistic regression was conducted to determine the effects of indoor kitchen, sleeping area, and environmental tobacco smoke (ETS) exposure on the prevalence of asthma-like symptoms and asthma in adults, with other sociodemographic factor variables as controls. Chi-squared tests were conducted to compare the prevalence of asthma symptoms between subjects with high kitchen risk scores and those with low kitchen risk scores. Spearman's correlation was employed to determine the correlation between $\mathrm{PM}_{2.5}$ exposure and pulmonary function in adults in winter. A $P$-value $<0.05$ was considered significant.

\section{Results}

\section{Population characteristics}

In this study, 1207 adult residents participated in the survey conducted in winter and 610 participated in the survey conducted in summer. The residents had a mean age of $45.5 \mathrm{y}, 51.3 \%$ of which were female. Moreover, $4.4 \%$ of the total consisted of ethnic minorities, $83 \%$ were married, $64 \%$ were at least high school-educated, $20 \%$ were overweight (BMI $\geq 23 \mathrm{~kg} / \mathrm{m}^{2}$ ), $22 \%$ experienced asthma-like symptoms and asthma attacks during childhood, 31\% reported familial history of asthma-like symptoms and asthma, $80 \%$ had high household income (monthly per capita income > US \$300), and 20\% reported occupational exposure to dust/gas. The characteristics of the 1207 residents are listed in Table 1, as described in our previous study [2] (Table 1).

More adults opened their kitchen windows in summer $(83.9 \%)$ than in winter $(74.7 \%)(p<0.001)$, with statistically significant difference. A coal stove was used to warm or cook food by $38.8 \%$ of the residents in winter vs. $8.1 \%$ in summer $(p<0.001)$. Cooking time of $60 \mathrm{~min}$ daily was reported by $7.6 \%$ of the residents in winter vs. $14.8 \%$ in summer $(p<0.001)$. About $75.6 \%$ of the adults used a fan or a range hood in their kitchen in winter vs. $3.0 \%$ in summer $(\mathrm{p}<0.001)$. Pest-infested kitchen was reported by nearly $1 \%$ of adults in winter vs. $5 \%$ in summer $(p<0.05)$ (Table 2).

With regard to sleeping-area risk factors, a feather or hairpiece mattress in winter was used by $14.2 \%$ of the adults in winter vs. $2.0 \%$ in summer $(p<0.001)$. About $31.1 \%$ of the adults had indoor pets in winter vs. $20.2 \%$ in summer $(\mathrm{p}<0.001)$. Mold growth was reported by $7.0 \%$ of the adults in winter vs. $2.8 \%$ in summer $(p<$ $0.001)$. More than $7 \%$ of the adults had new furniture in winter vs. $2.8 \%$ in summer. Domestic decorations and fitment were used by $5.0 \%$ of the adults in winter vs. $1.8 \%$ in summer $(p<0.001)$. Nearly $18 \%$ of the residents reported exposure to second-hand smoke in winter vs. $84 \%$ in summer $(p<0.001)$ (Table 2$)$.

\section{Comparison of the prevalence of asthma-like symptoms and asthma as well as outcomes of logistic regression analysis between winter and summer}

Table 3 presents the estimated effects of kitchen location, smoking status, cooking oil fumes, pets, stove used for cooking or warming, and second-hand smoke, mattress use history, and mold in bedroom in winter and/or summer, in addition to selected socioeconomic and demographic variables, on the prevalence of such symptoms suffered by the adult residents.

Differences in factors causing asthma-like symptoms and asthma in Zunyi were observed between summer and winter. After adjustments for host factors, such as gender and educational level, an increase of one year in age was found to have a $2.9 \%$ increase in asthma-like symptoms and asthma [95\% confidence interval (CI), $1.00-1.06$ ] in winter vs. $3.1 \%(95 \% \mathrm{CI}, 1.01-1.05)$ such increase in summer. The odds ratio (OR) for asthma-like symptoms and asthma in adults with BMI of at least $23.0 \mathrm{~kg} / \mathrm{m}^{2}$ relative to $\mathrm{BMI}<18.5 \mathrm{~kg} / \mathrm{m}^{2}$ was $1.73(95 \%$ CI, 1.11-2.69) in winter vs. 1.30 (95\% CI, 0.79-2.14) in summer. Adult residents who experienced asthma-like symptoms and asthma in childhood were significantly associated with those who experienced asthma-like symptoms and asthma in adulthood, with OR of 12.24 (95\% CI, 5.69-26.33) in winter vs. 6.88 (95\% CI, 2.9915.77 ) in summer. Subjects with a family history of asthma also showed significantly higher prevalence of asthma-like symptoms and asthma compared with subjects without such history $[\mathrm{OR}=2.45(95 \% \mathrm{CI}, 1.21$ $4.97)$ in winter vs. $\mathrm{OR}=1.93(95 \% \mathrm{CI}, 0.87-4.32)$ in summer]. Among the home environment factors, the coal stove used for cooking or warming and the prevalence of adult asthma-like symptoms and asthma exhibited a statistically significant association [OR $=1.83(95 \%$ $\mathrm{CI}, 1.20-2.81)$ in winter vs. OR $=2.3(95 \% \mathrm{CI}, 1.35-3.98)$ in summer]. Adult residents with exposure to cooking oil fumes were at a considerably higher risk of suffering from such symptoms $[\mathrm{OR}=2.65(95 \% \mathrm{CI}, 1.25-5.61)$ in 
Table 1 Socio-demographic characteristics of the respondents

\begin{tabular}{|c|c|c|}
\hline \multirow[t]{2}{*}{ Socio-demographic characteristics } & \multicolumn{2}{|l|}{ Subject } \\
\hline & Number $(n=1207)$ & Percentage (\%) \\
\hline \multicolumn{3}{|l|}{ Gender } \\
\hline Male & 588 & 48.7 \\
\hline Female & 619 & 51.3 \\
\hline \multicolumn{3}{|l|}{ Age distribution (years) } \\
\hline $18-39$ & 493 & 40.8 \\
\hline $40-59$ & 485 & 40.2 \\
\hline$\geq 60$ & 229 & 19.0 \\
\hline \multicolumn{3}{|l|}{ Ethnic group } \\
\hline Han & 1154 & 95.6 \\
\hline Ethnic of minority & 53 & 4.4 \\
\hline \multicolumn{3}{|l|}{ Marital status } \\
\hline Not-married & 208 & 17.2 \\
\hline Married & 999 & 82.8 \\
\hline \multicolumn{3}{|l|}{ Education } \\
\hline Senior high school and above & 771 & 63.9 \\
\hline Below senior high school & 436 & 36.1 \\
\hline \multicolumn{3}{|l|}{ BMI $\left(\mathrm{kg} / \mathrm{m}^{2}\right)$} \\
\hline Underweight (BMI < 18.5 kg/m²) & 212 & 17.6 \\
\hline Normal weight $\left(18.5 \leq \mathrm{BMl}<23 \mathrm{~kg} / \mathrm{m}^{2}\right)$ & 757 & 62.7 \\
\hline Overweight (BMI $\geq 23$ kg/m²) & 238 & 19.7 \\
\hline \multicolumn{3}{|c|}{ Asthma-like symptoms and asthma in childhood } \\
\hline Yes & 268 & 22.2 \\
\hline No & 939 & 77.8 \\
\hline \multicolumn{3}{|c|}{ Familial history of asthma-like symptoms and asthma } \\
\hline Yes & 375 & 31.1 \\
\hline No & 832 & 68.9 \\
\hline \multicolumn{3}{|l|}{ Monthly household income } \\
\hline Low household income & 247 & 20.5 \\
\hline High household income & 960 & 79.5 \\
\hline \multicolumn{3}{|l|}{ Occupational exposure to dust or gas } \\
\hline Yes & 242 & 20.0 \\
\hline No & 965 & 80.0 \\
\hline
\end{tabular}

winter vs. $\mathrm{OR}=7.93$ (95\% CI, 2.54-24.75) in summer], compared with those without such exposure. Compared with the controls, the adult residents with pets were 2.97 times more likely to develop such symptoms in winter (OR = 2.97; 95\% CI, 1.347-6.527); meanwhile, having pets can be a protective factor for asthma-like symptoms $(\mathrm{OR}=0.42$; 95\% CI, 0.12-1.53) in summer. The adjusted ORs for experiencing asthma-like symptoms and asthma were nearly 3 times higher in winter vs. 1.5 times higher in summer among the subjects who were then smokers, compared with those who had never smoked $(\mathrm{OR}=2.68$; $95 \% \mathrm{CI}, 1.670-4.284$ vs. $\mathrm{OR}=1.55 ; 95 \% \mathrm{CI}, 0.97-2.46)$.
The odds of suffering from asthma-like symptoms and asthma were about 4 times higher in winter vs. 3 times higher in summer among the adult residents with exposure to second-hand smoke than those without such exposure $(\mathrm{OR}=3.96 ; 95 \% \mathrm{CI}, 1.81-8.70$ vs. $\mathrm{OR}=2.95$; 95\% CI, 1.14-7.61). In addition, in summer rather than winter, the risk of asthma attack was about 8 times $(\mathrm{OR}=$ 7.70, 95\% CI, 1.90-31.13) higher among subjects with exposure to molds than those without such exposure. With other controlled variables, history of mattress use $>5$ years also seemed to be a protective factor $(\mathrm{OR}=0.28$; $95 \% \mathrm{CI}$, 0.14-0.56) for asthma and asthma morbidity (Table 3 ). 
Table 2 Comparison between indoor (kitchen, sleeping area, ETS) risk exposures among respondents in winter and summer

\begin{tabular}{|c|c|c|c|c|}
\hline \multirow[t]{2}{*}{ Variables } & \multirow{2}{*}{$\begin{array}{l}\text { Winter } \\
\text { Number of respondents } \\
\text { (percentage,\%) }(n=1207)\end{array}$} & \multirow{2}{*}{$\begin{array}{l}\text { Summer } \\
\text { Number of respondents } \\
\text { (percentage,\%) }(n=610)\end{array}$} & \multirow[t]{2}{*}{$x^{2 a}$} & \multirow[t]{2}{*}{$p$ value } \\
\hline & & & & \\
\hline \multicolumn{5}{|l|}{ Kitchen location } \\
\hline Separated from other rooms & $1158(95.9)$ & $587(96.2)$ & \multirow[t]{2}{*}{0.089} & \multirow[t]{2}{*}{0.756} \\
\hline Within living rooms or bedrooms & $49(4.1)$ & $23(3.8)$ & & \\
\hline \multicolumn{5}{|l|}{ Kitchen size } \\
\hline$\geq 4 m^{2}$ & $1042(86.3)$ & $526(86.2)$ & \multirow[t]{2}{*}{0.003} & \multirow[t]{2}{*}{0.095} \\
\hline$<4 \mathrm{~m}^{2}$ & $165(13.7)$ & $84(13.8)$ & & \\
\hline \multicolumn{5}{|l|}{ Frequency of opening kitchen windows } \\
\hline Occasionally or never & $45(3.7)$ & $0(0)$ & \multirow[t]{4}{*}{49.822} & \multirow[t]{4}{*}{$<0.001^{* * *}$} \\
\hline Sometimes & $118(9.8)$ & $20(3.3)$ & & \\
\hline Most of the time & $142(11.8)$ & $78(12.8)$ & & \\
\hline Always & $902(74.7)$ & $512(83.9)$ & & \\
\hline \multicolumn{5}{|l|}{ Stove used for cooking or warming } \\
\hline Clean fuel stove & $476(39.4)$ & $371(60.8)$ & \multirow[t]{3}{*}{188.560} & \multirow[t]{3}{*}{$<0.001^{* * *}$} \\
\hline Fuel mix stove & $263(21.8)$ & $190(31.1)$ & & \\
\hline Coal stove & $468(38.8)$ & $49(8.1)$ & & \\
\hline \multicolumn{5}{|l|}{ Duration of cooking per day } \\
\hline$<30 \mathrm{~min}$ & $581(48.1)$ & $384(63.0)$ & \multirow[t]{3}{*}{90.253} & \multirow[t]{3}{*}{$<0.001^{* * *}$} \\
\hline $30-60 \mathrm{~min}$ & $534(44.2)$ & $136(22.3)$ & & \\
\hline$>60 \min$ & $92(7.6)$ & $90(14.8)$ & & \\
\hline \multicolumn{5}{|l|}{ Cooking oil fumes } \\
\hline Never or seldom & $819(67.9)$ & $427(70.0)$ & \multirow[t]{2}{*}{0.866} & \multirow[t]{2}{*}{0.352} \\
\hline Frequently or sometimes & $388(32.1)$ & $183(30.0)$ & & \\
\hline \multicolumn{5}{|l|}{ Frequency of fan or range hood usage } \\
\hline Never & $65(5.4)$ & $22(3.6)$ & \multirow[t]{4}{*}{102.680} & $<0.001^{* * *}$ \\
\hline Seldom & $46(3.8)$ & $107(17.5)$ & & \\
\hline Sometimes & $183(15.2)$ & $97(15.9)$ & & \\
\hline Always & $913(75.6)$ & $384(3.0)$ & & \\
\hline Kitchen infested with pests & & & & \\
\hline Never & $1071(88.7)$ & $553(86.2)$ & 7.730 & $0.021^{*}$ \\
\hline Seldom & $122(10.1)$ & $43(8.4)$ & & \\
\hline Sometimes & $14(1.2)$ & $14(5.4)$ & & \\
\hline Person(s) sharing in one bedroom & & & & \\
\hline$\geq 3$ persons & $222(18.4)$ & $113(18.5)$ & 0.005 & 0.945 \\
\hline$<3$ persons & $985(81.6)$ & $497(81.5)$ & & \\
\hline Carpet & & & & \\
\hline No & $1134(94.0)$ & $579(94.9)$ & 0.701 & 0.402 \\
\hline Yes & $73(6.0)$ & $31(5.1)$ & & \\
\hline Carpet use history (years) & & & & \\
\hline$\leq 1 \mathrm{y}$ & $1143(94.7)$ & $584(95.7)$ & 1.412 & 0.494 \\
\hline $1-5 y$ & $49(4.1)$ & $18(3.0)$ & & \\
\hline$>5 y$ & $15(1.2)$ & $8(1.3)$ & & \\
\hline
\end{tabular}

Mattress material 
Table 2 Comparison between indoor (kitchen, sleeping area, ETS) risk exposures among respondents in winter and summer (Continued)

\begin{tabular}{|c|c|c|c|c|}
\hline \multirow[t]{2}{*}{ Variables } & \multirow{2}{*}{$\begin{array}{l}\text { Winter } \\
\text { Number of respondents } \\
\text { (percentage, } \%)(n=1207)\end{array}$} & \multirow{2}{*}{$\begin{array}{l}\text { Summer } \\
\text { Number of respondents } \\
\text { (percentage, } \%)(n=610)\end{array}$} & \multirow[t]{2}{*}{$x^{2 a}$} & \multirow[t]{2}{*}{$p$ value } \\
\hline & & & & \\
\hline Cloth or no mattress & $785(65.0)$ & $503(82.5)$ & 83.037 & $<0.001^{* * *}$ \\
\hline Foam or grass/grain husks & $251(20.8)$ & 95 (15.6) & & \\
\hline Feather or hairpiece & $171(14.2)$ & $12(2.0)$ & & \\
\hline \multicolumn{5}{|l|}{ Mattress use history (years) } \\
\hline$\leq 1 y$ & $509(42.2)$ & $279(45.7)$ & 2.156 & 0.340 \\
\hline $1-5 y$ & $582(48.2)$ & $274(44.9)$ & & \\
\hline$>5 y$ & $116(9.6)$ & $57(9.3)$ & & \\
\hline \multicolumn{5}{|l|}{ Pillow material stuffed } \\
\hline Cloth or no pillow & $954(79.1)$ & $535(87.7)$ & 45.642 & $<0.001^{* * *}$ \\
\hline Grass or foam & $127(10.5)$ & $65(10.7)$ & & \\
\hline Feather & $126(10.4)$ & $10(1.6)$ & & \\
\hline \multicolumn{5}{|l|}{ Keep pets } \\
\hline No & $937(68.9)$ & $487(79.8)$ & 106.246 & $<0.001^{* * *}$ \\
\hline Yes & $270(31.1)$ & $123(20.2)$ & & \\
\hline \multicolumn{5}{|l|}{ Pet allowed in bedroom } \\
\hline No & $1135(94.0)$ & $568(93.1)$ & 0.583 & 0.445 \\
\hline Yes & $72(6.0)$ & $42(6.9)$ & & \\
\hline \multicolumn{5}{|l|}{ Water damage } \\
\hline No & $1112(92.1)$ & $575(94.3)$ & 2.775 & 0.096 \\
\hline Yes & $95(7.9)$ & $35(5.7)$ & & \\
\hline \multicolumn{5}{|l|}{ Musty air in bedroom } \\
\hline No & $1108(91.8)$ & $586(96.1)$ & 11.694 & $0.001^{* *}$ \\
\hline Yes & $99(8.2)$ & $24(3.9)$ & & \\
\hline \multicolumn{5}{|l|}{ Mold in bedroom } \\
\hline No & $1122(93.0)$ & $593(97.2)$ & 13.848 & $<0.001^{* * *}$ \\
\hline Yes & $85(7.0)$ & $17(2.8)$ & & \\
\hline \multicolumn{5}{|l|}{ New furniture } \\
\hline No & $1119(92.7)$ & $593(97.2)$ & 15.097 & $<0.001^{* * *}$ \\
\hline Yes & $88(7.3)$ & $17(2.8)$ & & \\
\hline \multicolumn{5}{|l|}{ Decoration and fitment } \\
\hline No & $1147(95.0)$ & $599(98.2)$ & 10.829 & $0.001^{* *}$ \\
\hline Yes & $60(5.0)$ & $11(1.8)$ & & \\
\hline \multicolumn{5}{|l|}{ Smoking status } \\
\hline Non-smokers & $688(57.0)$ & $365(59.8)$ & 1.803 & 0.406 \\
\hline Ex-smokers & $167(13.8)$ & $85(13.9)$ & & \\
\hline Current smokers & $352(29.2)$ & $160(26.2)$ & & \\
\hline \multicolumn{5}{|c|}{ Exposure to second-hand smoke, ETS } \\
\hline Yes & $222(18.4)$ & $518(84.4)$ & 742.80 & $<0.001^{* * *}$ \\
\hline No & $985(81.6)$ & $92(15.6)$ & & \\
\hline
\end{tabular}


Table 3 Comparison of the prevalence of asthma-like symptoms and asthma and outcome of logistic regression analysis in Zunyi in winter vs. summer

\begin{tabular}{|c|c|c|c|c|c|c|c|c|}
\hline \multirow[t]{3}{*}{ Risk factors } & \multicolumn{4}{|l|}{ Winter } & \multicolumn{4}{|c|}{ Summer } \\
\hline & \multicolumn{8}{|c|}{ Prevalence of asthma-like symptoms and asthma } \\
\hline & B & Standard Error & OR $(95 \% \mathrm{Cl})$ & $P$ value & $\mathrm{B}$ & Standard Error & OR $(95 \% \mathrm{Cl})$ & $p$ value \\
\hline Constant & -13.655 & 1.785 & 0.000 & $<0.001^{* * *}$ & -8.255 & 1.511 & 0.000 & $<0.001^{* * *}$ \\
\hline Age, years & 0.029 & 0.014 & $1.030(1.003,1.058)$ & $0.030^{*}$ & 0.031 & 0.013 & $1.032(1.006,1.05)$ & $0.016^{*}$ \\
\hline BMI & 0.548 & 0.226 & $1.730(1.111,2.693)$ & $0.015^{*}$ & 0.262 & 0.253 & $1.299(0.791,2.135)$ & 0.301 \\
\hline $\begin{array}{l}\text { Asthma and asthma-related } \\
\text { symptoms in childhood }\end{array}$ & 2.505 & 0.391 & $12.239(5.690,26.329)$ & $<0.001^{* * *}$ & 1.928 & 0.424 & $6.877(2.994,15.767)$ & $<0.001^{* * *}$ \\
\hline $\begin{array}{l}\text { Familial history of asthma-like } \\
\text { symptoms and asthma }\end{array}$ & 0.897 & 0.361 & $2.452(1.209,4.971)$ & $0.013^{*}$ & 0.660 & 0.410 & $1.934(0.866,4.319)$ & 0.107 \\
\hline Kitchen location & 0.714 & 0.923 & $2.042(0.334,12.478)$ & 0.439 & 2.176 & 0.812 & $8.807(1.794,43.241)$ & $0.007^{* *}$ \\
\hline $\begin{array}{l}\text { Stove used for cooking or } \\
\text { warming }\end{array}$ & 0.608 & 0.217 & $1.836(1.200,2.810)$ & $0.005^{* *}$ & 0.841 & 0.276 & $2.318(1.349,3.982)$ & $0.002^{* *}$ \\
\hline Cooking oil fumes & 0.973 & 0.384 & $2.646(1.247,5.613)$ & $0.011^{*}$ & 2.070 & 0.581 & $7.926(2.538,24.753)$ & $<0.001^{* * *}$ \\
\hline Keep pets & 1.087 & 0.403 & $2.966(1.347,6.527)$ & $0.007^{* *}$ & -0.858 & 0.654 & $0.424(0.118,1.526)$ & 0.189 \\
\hline Smoking status & 0.984 & 0.240 & $2.675(1.670,4.284)$ & $<0.001^{* * *}$ & 0.436 & 0.236 & $1.546(0.973,2.457)$ & $0.065^{*}$ \\
\hline Second-hand smoke & 1.377 & 0.401 & $3.963(1.807,8.691)$ & $<0.001^{* * *}$ & 1.082 & 0.483 & $2.950(1.144,7.607)$ & $0.025^{*}$ \\
\hline Mattress use history & - & - & - & - & -1.270 & 0.354 & $0.281(0.140,0.562)$ & $<0.001^{* * *}$ \\
\hline Mold in bedroom & - & - & - & - & 2.041 & 0.713 & $7.696(1.903,31.127)$ & $0.004^{* *}$ \\
\hline
\end{tabular}

Logistic regression, $\mathbf{a}=0.05,{ }^{*}$ significant at $p<0.05,{ }^{*}$ significant at $p<0.01,{ }^{* * *}$ significant at $p<0.001$

\section{Effects of environment and personal risk factors on} asthma-like symptoms and asthma in winter and summer In the winter survey, 158 of the 1207 adult residents reported experiencing asthma-like symptoms and asthma, whereas 1049 adults reported no such experience. In reports without asthma and asthma related symptoms, the median (25th and 75th percentiles) kitchen risk score and sleeping-area risk score were 6.0 (4.0-7.0) and 2.0 (1.0-4.0), respectively. The median (25th and 75th percentiles) kitchen risk scores among the subjects with such symptoms and those without such symptoms were $6.0(5.0-8.0)$ and $6.0(4.0-7.0)$, respectively. Significant difference was indicated between those with and without such symptoms $(p<0.001)$. The median $(25$ th and 75 th percentiles) scores for the sleeping area risk factor among the subjects with and without such symptoms were $3.0(1.0-5.0)$ and $2.0(1.0-4.0)$, respectively, The difference between those with and without such symptoms was statistically significant $(\mathrm{p}<0.001)$ (Table 4$)$.

Among the 610 residents surveyed in summer, 46 reported having experienced asthma-like symptoms and asthma, whereas 564 adults reported no such experience. For studies in which asthma and asthma related symptoms were reported, the median (25th and 75th percentiles) kitchen risk score and sleeping-area risk score were $2.0(1.0-5.0)$ and $2.0(1.0-3.0)$, respectively. The median (25th and 75th percentiles) kitchen risk scores among the subjects with such symptoms and those without such symptoms were $3.5(2.0-7.0)$ and 2.0 (1.0-5.0), respectively, Significant difference was indicated between those with and without such symptoms $(p<0.01)$ . The median (25th and 75th percentiles) scores for the sleeping area risk factor in the two groups were 2.0 (0.75-4.25) and 2.0 (1.0-3.0), respectively, but no significant difference was observed between the two groups $(p>0.05)$ (Table 4$)$.

The median (25th and 75th percentiles) score for the kitchen risk factor was 6.0 (4.0-7.0) among 1207 adults in the winter survey and $2.0(1.0-5.0)$ in the summer survey among 610 adults; consequently, the subjects with a kitchen risk score of 6 in winter or 2 and above in summer were categorized into subjects with a high kitchen risk score. Conversely, subjects with kitchen risk scores of 6 and below in winter or 2 and below in summer were classified into subjects with low kitchen risk scores. In the winter survey, 77 adults with high kitchen risk scores experienced asthma-like symptoms and asthma, whereas 81 adults with low kitchen risk scores reported experiencing such symptoms, Significant difference in the prevalence of such symptoms was found between those with high kitchen risk scores and those with low kitchen risk scores $(p<0.01)$. In the summer survey, 30 adults with high kitchen risk scores and 16 adults with low kitchen risk scores experienced such symptoms, respectively. Significant difference in the prevalence of such symptoms was indicated between those with high kitchen risk scores and those with low kitchen risk scores $(p<0.05)$ (Table 5$)$. 
Table 4 Comparison of the median kitchen risk score and sleeping-area risk score among subjects with asthma-like symptoms and asthma and those without such symptoms in winter and summer

\begin{tabular}{|c|c|c|c|c|}
\hline \multirow[t]{2}{*}{ Asthma-like symptoms and asthma } & \multicolumn{2}{|l|}{ Winter $(n=1207)$} & \multicolumn{2}{|l|}{ Summer $(n=610)$} \\
\hline & $\begin{array}{l}\text { Median score for kitchen } \\
\text { risk factor ( } 25 \text { th, } 75 \text { th } \\
\text { percentiles) }\end{array}$ & $\begin{array}{l}\text { Median score for sleeping- } \\
\text { area risk factor (25th, } 75 \text { th } \\
\text { percentiles) }\end{array}$ & $\begin{array}{l}\text { Median score for kitchen } \\
\text { risk factors ( } 25 \text { th, } 75 \text { th } \\
\text { percentiles) }\end{array}$ & $\begin{array}{l}\text { Median score for sleeping } \\
\text { area risk factors }(25 \text { th, } 75 \text { th } \\
\text { percentiles) }\end{array}$ \\
\hline $\begin{array}{l}\text { Subjects with asthma-like symptoms } \\
\text { and asthma }\end{array}$ & $6.0(5.0-8.0)$ & $3.0(1.0-5.0)$ & $3.5(2.0-7.0)$ & $2.0(0.75-4.25)$ \\
\hline $\begin{array}{l}\text { Subjects without asthma-like } \\
\text { symptoms and asthma }(n=1049)\end{array}$ & $6.0(4.0-7.0)$ & $2.0(1.0-4.0)$ & $2.0(1.0-5.0)$ & $2.0(1.0-3.0)$ \\
\hline$Z$ value & $-4.481^{\mathrm{a}}$ & $-4.007^{\mathrm{a}}$ & $-3.06^{\mathrm{a}}$ & $-1.46^{\mathrm{a}}$ \\
\hline$p$ value & $<0.001^{* * *}$ & $<0.001^{* * *}$ & $0.002^{* *}$ & 0.144 \\
\hline
\end{tabular}

${ }^{a}$ Nonparametric test (Mann-Whitney $\mathrm{U}$ test), $\mathrm{a}=0.05 ;{ }^{*}$ significant at $p<0.05$, ${ }^{*}$ significant at $p<0.01,{ }^{* * *}$ significant at $p<0.001$

Analogously, the median (25th and 75th percentiles) score for the sleeping-area risk factors was $2.0(1.0-4.0)$ among the 1207 adults in the winter survey and 2.0 (1.0-3.0) among the 610 adults in the summer survey. Accordingly, the subjects with sleeping-area risk scores of 2 and above in winter or 2 and above in summer were categorized into subjects with high sleeping-area risk scores. By contrast, the subjects with sleeping-area risk scores of 2 and below in winter or 2 and below in summer were categorized into subjects with low sleepingarea risk scores. A total of 92 adults with high sleepingarea risk scores and 66 adults with low sleeping-area risk scores reported having experienced asthma-like symptoms and asthma in the winter survey. Significant difference was observed between those with high or low sleeping-area risk scores $(p<0.01)$. Asthma-like symptoms and asthma were reported in 16 adults with high sleeping-area risk scores and 30 adults with low sleeping-area risk scores in the summer survey; however, no significant difference was found between the two aforementioned groups $(p>0.05)$ (Table 6).

\section{Comparison of indoor and outdoor relative $\mathrm{PM}_{2.5}$ concentrations in winter and summer}

Figure 2 shows that the relative $\mathrm{PM}_{2.5}$ concentrations (cpm) in the kitchen $(\mathrm{z}=-5.583, p<0.001)$ and sleeping area $(\mathrm{z}=$ $-5.587, \mathrm{p}<0.001)$ in winter were significantly higher than those in summer for all 20 houses. However, the outdoor relative $\mathrm{PM}_{2.5}$ concentration $(\mathrm{z}=-5.420, p<0.001)$ in summer was significantly higher than that in winter.

\section{Comparison of the effects of indoor environmental risk factors on variations in pulmonary function parameters (FVC, FEV 1, FEV $_{1} /$ FVC, and PEFR)}

Table 7 compares the pulmonary function in summer with that in winter among 46 residents who reported experiencing asthma-like symptoms and asthma in summer. Wilcoxon signed-rank tests were utilized to determine whether significant difference in changes in pulmonary function (FVC, $\mathrm{FEV}_{1}, \mathrm{FEV}_{1} / \mathrm{FVC}$, and PEFR) was present between summer and winter. The FVC, $\mathrm{FEV}_{1}$, and PEFR of the subjects in winter were lower than those in summer $(p<0.001)$. The subjects exhibited a significant decrease in $\mathrm{FEV}_{1} / \mathrm{FVC}$ in summer relative to that in winter $(p<$ $0.001)$. Significant differences in the four parameters was observed between summer and winter $(p<0.001)$.

Relationship between indoor and outdoor relative $\mathrm{PM}_{2.5}$ concentrations and pulmonary function (FVC, $\mathrm{FEV}_{1}, \mathrm{FEV}_{1}$ / FVC, and PEFR) in winter and summer

Figures 3 and 4 show that a significant negative correlation exists between the pulmonary function test parameters of 86 adult residents and the relative $\mathrm{PM}_{2.5}$ concentrations of the indoor kitchen in the winter survey; however, no significant correlation was found in the summer survey [13] (FVC: $\mathrm{r}=-0.250, p=0.020$ vs. $\mathrm{r}=-$

Table 5 Differences in the prevalence of asthma-like symptoms and asthma between the subjects with high and low kitchen risk scores in winter and summer

\begin{tabular}{|c|c|c|c|c|}
\hline \multirow[t]{3}{*}{ Kitchen risk factors } & \multicolumn{2}{|l|}{ Winter } & \multicolumn{2}{|l|}{ Summer } \\
\hline & \multicolumn{4}{|c|}{$\overline{\text { Asthma-like symptoms and asthma }}$} \\
\hline & Yes $(n)$ & No $(n)$ & Yes (n) & No $(n)$ \\
\hline Subjects with high kitchen risk score & 77 & 384 & 30 & 267 \\
\hline Subjects with low kitchen risk score & 81 & 665 & 16 & 297 \\
\hline Pearson Chi-square & $8.556^{\mathrm{a}}$ & & $5.441^{\mathrm{a}}$ & \\
\hline$p$ value & $0.002^{* *}$ & & $0.014^{*}$ & \\
\hline
\end{tabular}

${ }^{a}$ Chi-square test, $\mathbf{a}=0.05 ;{ }^{*}$ significant at $p<0.05,{ }^{*}$ significant at $p<0.01$ 
Table 6 Difference in the prevalence of asthma-like symptoms and asthma between subjects with high and low sleeping-area risk scores in winter and summer

\begin{tabular}{|c|c|c|c|c|}
\hline \multirow[t]{3}{*}{ Sleeping area risk factors } & \multicolumn{2}{|l|}{ Winter } & \multicolumn{2}{|c|}{ Summer } \\
\hline & \multicolumn{4}{|c|}{ Asthma-like symptoms and asthma } \\
\hline & Yes $(n)$ & No $(n)$ & Yes (n) & No $(n)$ \\
\hline Subjects with high sleeping-area risk scores & 92 & 480 & 16 & 147 \\
\hline Subjects with low sleeping-area-risk scores & 66 & 569 & 30 & 417 \\
\hline Pearson Chi-square & \multicolumn{2}{|l|}{$8.564^{\mathrm{a}}$} & \multicolumn{2}{|l|}{$1.651^{\mathrm{a}}$} \\
\hline$p$ value & \multicolumn{2}{|l|}{$0.002^{* *}$} & \multicolumn{2}{|l|}{0.134} \\
\hline
\end{tabular}

${ }^{\mathrm{a}}$ Chi-square test, $\mathrm{a}=0.05 ;{ }^{*}$ significant at $p<0.05,{ }^{* *}$ significant at $p<0.01$

0.228, $p=0.152 ; \mathrm{FEV}_{1}: \mathrm{r}=-0.267, p=0.013 ; \mathrm{FEV}_{1} / \mathrm{FVC}$ : $\mathrm{r}=-0.422, p<0.001$ vs. $\mathrm{r}=0.284, p=0.072$; PEFR $\mathrm{r}=-$ $0.257, p=0.017$ vs. $\mathrm{r}=-0.187, p=0.241$ ). The pulmonary function test parameters and the relative $\mathrm{PM}_{2.5}$ concentrations of the indoor sleeping area exhibited a significant negative correlation in the winter survey; however, no significant correlation was observed in the summer survey (FVC: $\mathrm{r}=-0.234, p=0.030$ vs. $\mathrm{r}=-0.215, p=0.177 ; \mathrm{FEV}_{1}$ : $\mathrm{r}=-0.235, \mathrm{p}=0.030$ vs. $\mathrm{r}=-0.175, p=0.274 ; \mathrm{FEV}_{1} / \mathrm{FVC}$ : $\mathrm{r}=-0.391, \mathrm{p}<0.001$ vs. $\mathrm{r}=0.260, p=0.100 ;$ PEFR $\mathrm{r}=-$ $0.232, p=0.032$ vs. $\mathrm{r}=-0.176, p=0.270$ ) (Fig. 3). In addition, no significant differences in $\mathrm{FVC}, \mathrm{FEV}_{1}, \mathrm{FEV}_{1} /$ FVC, and PEFR were observed between the pulmonary function test parameters and the relative outdoor kitchen $\mathrm{PM}_{2.5}$ concentrations in winter and summer $(p>0.05)$.

\section{Discussion}

The prevalence of asthma-like symptoms and asthma has markedly increased over the last decade in China and Western industrial countries. Indoor environmental quality significantly affects the occurrence of asthma attacks. In this study, exposure to indoor risk factors (e.g., stove used for cooking or warming, cooking oil fumes, and smoking status) was associated with the increased risks of asthma-like symptoms and asthma among adult residents, particularly in winter. The $\mathrm{PM}_{2.5}$ levels in the kitchen and the sleeping area were higher in winter than in summer. A negative relationship between lung function and the relative $\mathrm{PM}_{2.5}$ concentrations in the indoor kitchen and the sleeping area was also observed in winter rather than summer. The effect of exposure to indoor risk factors on lung function was greater in winter than in summer.

We previously reported that among the various risk factors, asthma in childhood, kitchen in the living room or bedroom, mixed fuel stove, cooking oil fumes, second-hand smoke, mold growth, and home furnishings were associated with increased risks of adult asthma-like symptoms and asthma [2]. Studies have found a similar association between specific indoor environmental

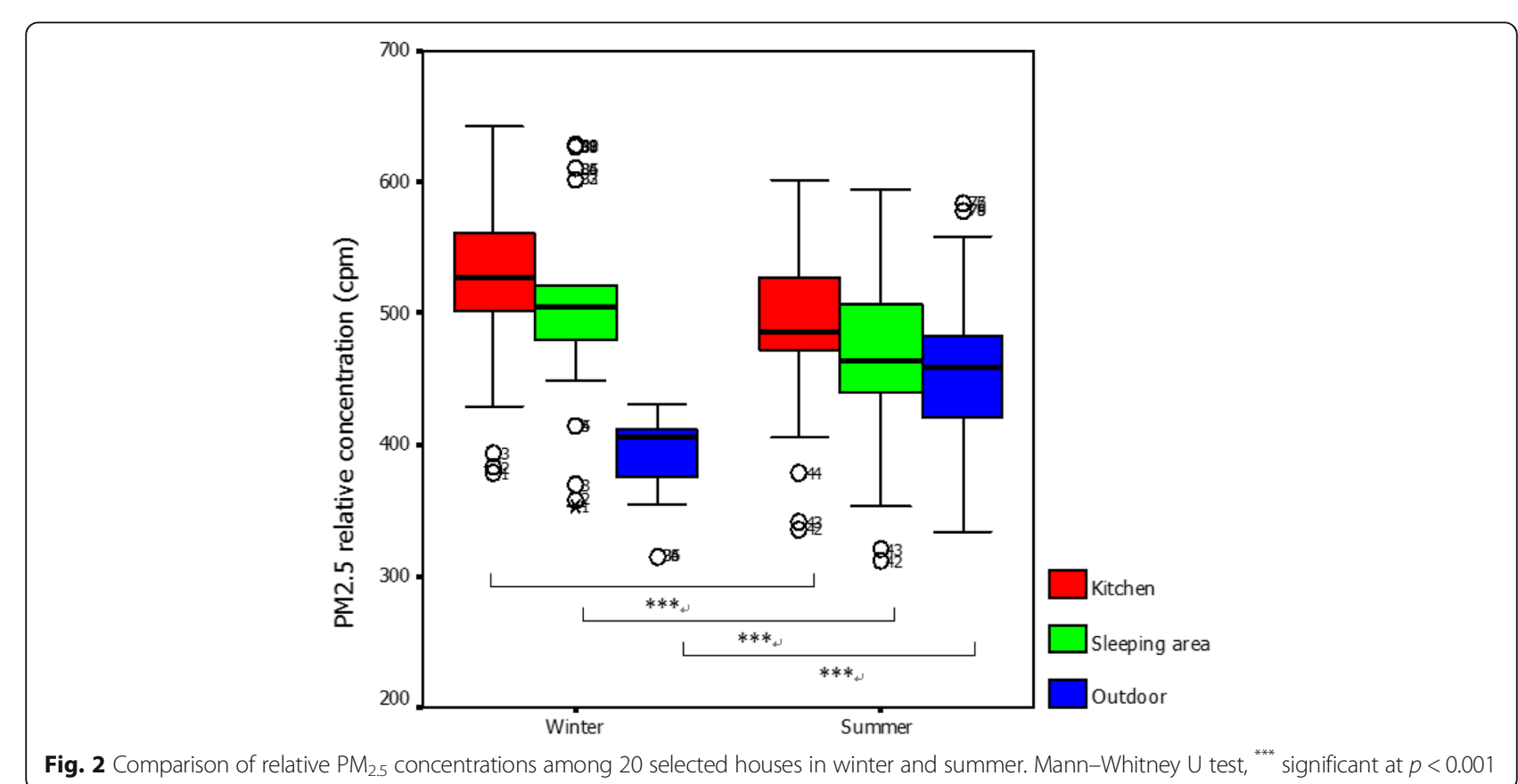

Fig. 2 Comparison of relative $\mathrm{PM}_{2.5}$ concentrations among 20 selected houses in winter and summer. Mann-Whitney $\mathrm{U}$ test, ${ }^{* * *}$ significant at $p<0.001$ 
Table 7 Paired comparison analysis of pulmonary function (FVC, FEV $1, F^{2} V_{1} / F V C$, and PEFR) in 46 adults in winter and summer

\begin{tabular}{|c|c|c|c|c|}
\hline \multirow{2}{*}{$\begin{array}{l}\text { Pulmonary function } \\
\text { parameters }\end{array}$} & \multicolumn{2}{|c|}{ Asthma-like symptoms and asthma } & \multirow[t]{2}{*}{ Z } & \multirow[t]{2}{*}{$p$ value } \\
\hline & Summer $(n=46)$ & Winter $(n=46)$ & & \\
\hline FVC in litres $(\mathrm{L})$ & $3.5(2.7-4.1)$ & $2.9(2.1-3.7)$ & $-5.91^{\mathrm{a}}$ & $<0.001^{* * *}$ \\
\hline $\mathrm{FEV}_{1}$ in litres $(\mathrm{L})$ & $3.3(2.4-3.8)$ & $2.7(1.8-3.5)$ & $-5.91^{\mathrm{a}}$ & $<0.001^{* * *}$ \\
\hline $\mathrm{FEV}_{1} / \mathrm{FVC}$ in percentage & $91.7(87.7-94.0)$ & $91.9(82.0-94.6)$ & $-2.91^{\mathrm{a}}$ & $<0.001^{* * *}$ \\
\hline PEFR in litres/min & $382.8(324.9-420.7)$ & $347.9(303.8-404.4)$ & $-5.89^{\mathrm{a}}$ & $<0.001^{* * *}$ \\
\hline
\end{tabular}

${ }^{a}$ Nonparametric test (Wilcoxon signed-rank test); ${ }^{*}$ significant at $p<0.05$; ${ }^{*}$ significant at $p<0.05$, ${ }^{* *}$ significant at $p<0.01,{ }^{* * *}$ significant at $p<0.001$

exposure and exacerbation of adult asthma [3, 14]. For the first time, potential sources of exposure to indoor air pollutants were quantified in detail and assigned a score for each exposure risk factor to evaluate the relationship between different degrees of exposure to indoor (i.e., in the kitchen and the bedroom) environmental contaminants and asthma morbidity in this study. Our results indicate that both the kitchen risk score and the sleeping-area risk score were significantly higher in adults with asthma morbidity than in those without, particularly in winter. Moreover, the prevalence of asthmalike symptoms and asthma was significantly greater in adults with high kitchen risk scores or high sleepingarea risk scores than in those with low scores in both seasons. These findings suggest that exposure to indoor risk factors, such as aerocontaminants from coal combustion, leads to asthma symptoms and exacerbations. Although an association between exposure to indoor pollutants and childhood asthma has been reported in the last two decades, few studies have focused on adult population.

Residents in underdeveloped areas in China still use stoves for cooking and warming, increasing coal consumption. Fu et al. (2016) conducted a cross-sectional survey by stratified random sampling in 7 cities in China. Coal cooking was found to be an independent determinant of indoor environment for asthma $(\mathrm{OR}=2.65)$ [15]. Kim et al. (2013) showed that coal cooking adversely affects indoor air quality [16]. The results of these two studies were consistent with our study, which found that the coal stove used for cooking or warming was significantly correlated to the prevalence of adult asthma and asthma morbidity in both seasons.

The relationship between indoor air pollution and poor pulmonary function has been demonstrated in numerous studies. In their cross-sectional study in the United States, Stephanie et al. found no significant associations between IAP exposure and pulmonary function in adults [15]. Several studies indicated a positive relationship between indoor environmental exposure and respiratory health. A randomized exposure study of pollution and respiratory effects in the United Kingdom showed an association between exposure to household air pollution from wood combustion and low level of lung function in nonsmoking women [16]. However, data relating indoor $\mathrm{PM}_{2.5}$ concentrations to lung function outcomes are limited. The results of our study are consistent with the findings by Yulia [17], that a significant negative correlation exists between pulmonary function and indoor relative $\mathrm{PM}_{2.5}$ concentration rather than outdoor relative $\mathrm{PM}_{2.5}$ concentration; however, correlation coefficients between -0.20 and -0.40 were considered low. An association between exposure to $\mathrm{PM}_{2.5}$ from indoor coal combustion and decreased lung function in adults has not been determined.

We found that the relative $\mathrm{PM}_{2.5}$ concentrations in the kitchen and the bedroom were higher in winter than in summer. The FVC, $\mathrm{FEV}_{1}$, and PEFR were lower in winter than in summer. Coal is the major domestic fuel for cooking and baking and warming households in most Zunyi households, particularly in winter. In winter, combustion of coal and natural gas in poorly ventilated homes exposes children and adults to high levels of PM, sulfur oxides $\left(\mathrm{SO}_{2}\right)$, and other air pollutants in Zunyi. In summer, many households using coal experience $\mathrm{CO}$ levels several times the national indoor air quality (IAQ) standard of $10 \mathrm{mg} / \mathrm{m}^{3}$ (equivalent to $9 \mathrm{ppm}$ ) [18], and in winter, the situation worsens, particularly in households using coal stove. Moreover, risks to respiratory health for many people may be increased because of exposure to excessively high indoor pollutants from poorly ventilated household stoves. The longer a household heats in winter, the more likely its members are to show impaired lung function. Regardless of the type of fuel used, the concentrations of both $\mathrm{PM}$ pollutants and $\mathrm{SO}_{2}$ were highest in winter when fuel consumption was greatest; meanwhile, the concentrations were lowest in summer when heating requirements were lower.

The current study has a number of limitations. Personal $\mathrm{PM}_{2.5}$ monitoring of cooks and noncooks spending most of their time at home to assess individual continuous exposures was not conducted. $\mathrm{PM}_{2.5}$ monitoring at home in both seasons was relatively short and should be performed during the entire winter and in summer. The cross-sectional design might find a weak association between risk factor exposure and respiratory health because of confounding from individual risk factors. 

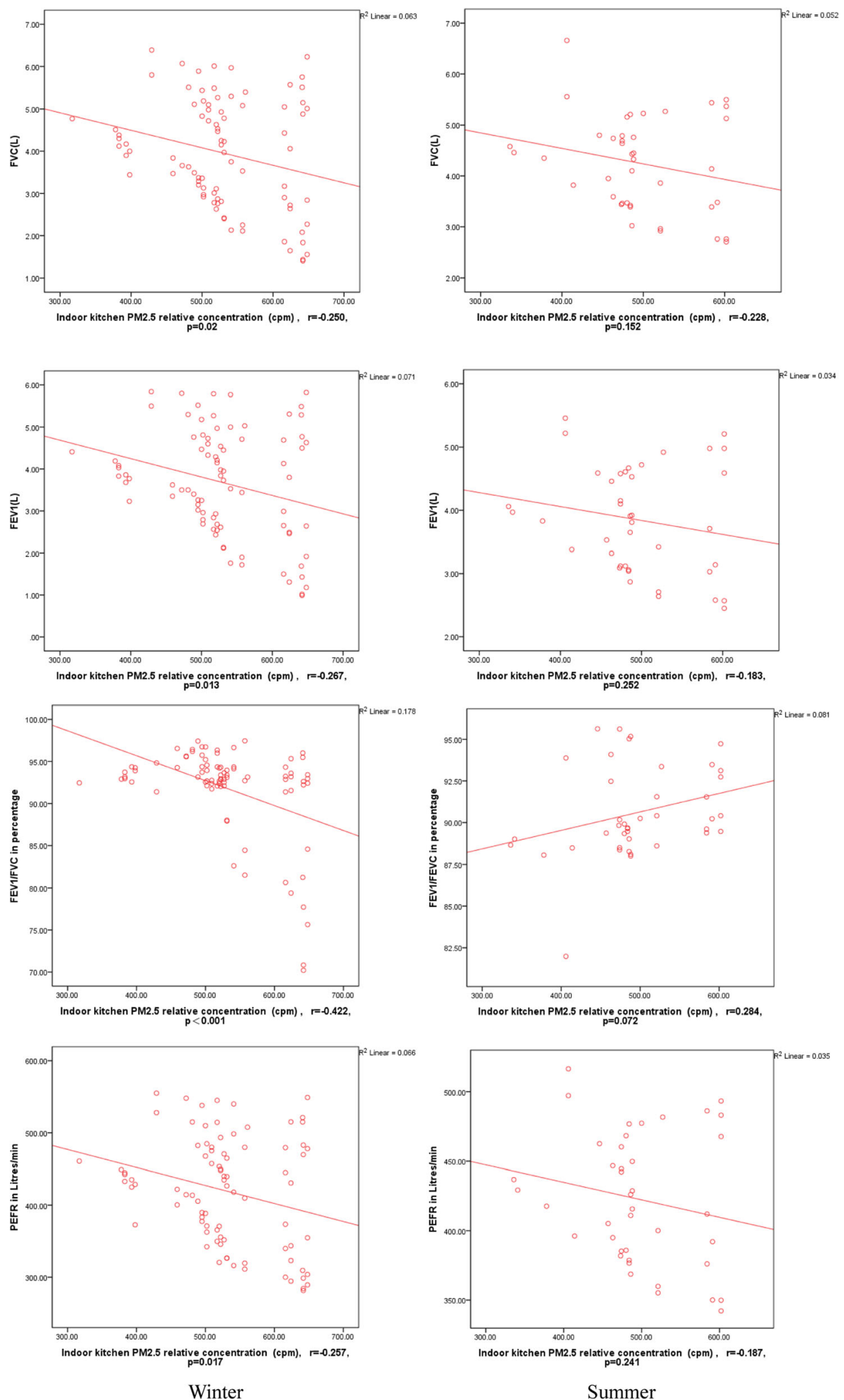

Fig. 3 Comparison of pulmonary function (FVC, $F E V_{1}, F E V_{1} / F V C$, and PEFR) in the adults and correlation of pulmonary function with kitchen $\mathrm{PM}_{2.5}$ exposure in winter and summer. Spearman correlation, r: Correlation coefficient 

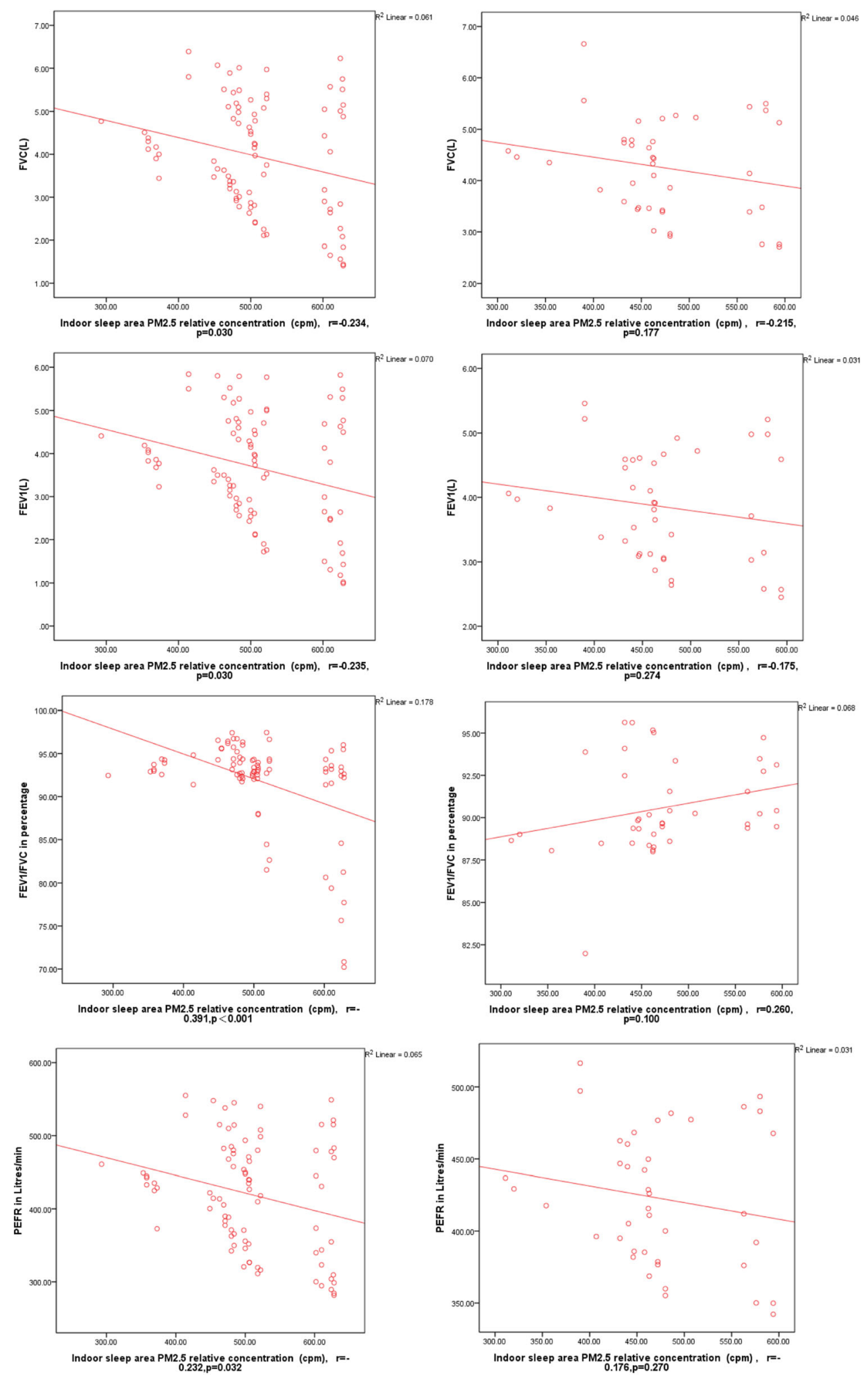

Winter

Summer

Fig. 4 Comparison of pulmonary function (FVC, $F E V_{1}, F E V_{1} / F V C$, and PEFR) in the adults and correlation of pulmonary function with sleeping area $\mathrm{PM}_{2.5}$ exposure in winter and summer. Spearman correlation, $\mathrm{r}$ : Correlation coefficient 


\section{Conclusion}

Exposure to indoor risk factors, such as aerocontaminants from coal combustion, has been hypothesized to cause asthma symptoms, as well as exacerbations, and decrease pulmonary function. The effect of exposure to indoor risk factors on respiratory health among adults was greater in winter than in summer.

\section{Additional files}

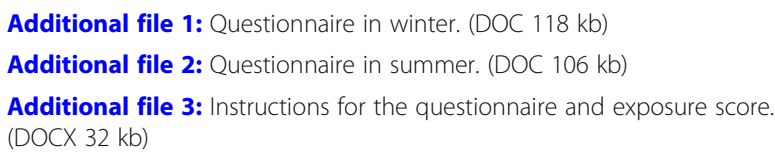

\section{Abbreviations}

Cl: Confidence interval; ECRHS II: European Community Respiratory Health Survey II; ETS: Environmental tobacco smoke; FEV ${ }_{1}$ : Forced expiratory volume in $1 \mathrm{~s}$; FVC: Forced vital capacity; IAP: Indoor air pollution; IAQ: Indoor air quality; OR: Odds ratio; PEFR: Peak expiratory flow rate; PM $_{25}$ : Particulate matter 2.5

\section{Acknowledgements}

Not applicable.

\section{Authors' contributions}

$Y J$ and $X J$ designed the study. LSX, YJ, JZg, LY, YY analyzed and interpreted the data. YJ, XJ conducted the survey work and sample collection. LSX and $Y J$ wrote the manuscript, $X J$ revised the manuscript. All the authors read and approved this paper.

\section{Funding}

This work was supported by the National Natural Science Foundation of China (81560527, 81760580); the Advanced Programs of Overseas Students Science and Technology Activities, Ministry of Human Resources and Social Security of the People's Republic of China [2016](08); the Key Program of Scientific and Technological Fund of Department of Science and Technology of Guizhou Province, China (2019-1466; 2018-1429); the Scientific and Technological Talent Support Program of the Educational Commission of Guizhou Province of China (KY[2018]054); the Fund for Key Discipline Construction in Zunyi Medical University (2015); the Scientific and Technological Fund of Department of Health of Guizhou Province, China (gzwjkj2016-1-045, gzwjkj2017-1-053); the Excellent Youth Science and Technique Talents of Guizhou Province [2017]5612; 15851 Project Talent in Zunyi municipal government, Guizhou Province (2018). The funding agencies did not take part in the study design, data collection and analysis, manuscript preparation, or decision to publish.

\section{Availability of data and materials}

All data and materials related to the study can be obtained through contacting the correspondent author at Xujie360@hotmail.com.

\section{Ethics approval and consent to participate}

The proposal of the study was reviewed and approved by the Zunyi Medical University. The study was also approved by the Zunyi Medical University Ethics Committee, and oral consent was obtained from participants prior to the interview.
Received: 25 July 2018 Accepted: 29 May 2019

Published online: 10 June 2019

\section{References}

1. Sussan TE, Ingole V, Kim JH, McCormick S, Negherbon J, Fallica J, et al. Source of biomass cooking fuel determines pulmonary response to household air pollution. Am J Respir Cell Mol Biol. 2014;50(3):538-48.

2. Jie $Y$, Isa ZM, Jie $X$, Ismail NH. Asthma and asthma-related symptoms among adults of an acid rain-plagued city in Southwest China: Prevalence and risk factors. Pol J Environ Stud. 2013;22(3):717-26.

3. Gordon SB, Bruce NG, Grigg J, Hibberd PL, Kurmi OP, Lam KB, et al. Respiratory risks from household air pollution in low and middle income countries. Lancet Respir Med. 2014;2(10):823-60.

4. Mentese S, Mirici NA, Otkun MT, Bakar C, et al. Association between respiratory health and indoor air pollution exposure in Canakkale. Turkey Build Sci. 2015;93:72-83.

5. McCormack MC, Belli AJ, Waugh D, Matsui EC, Peng RD, Williams DL, et al. Respiratory effects of indoor heat and the interaction with air pollution in chronic obstructive pulmonary disease. Ann Am Thorac Soc. 2016;13(12):2125-31.

6. Agrawal S, Yamamoto S. Effect of indoor air pollution from biomass and solid fuel combustion on symptoms of preeclampsia/eclampsia in Indian women. Indoor Air. 2015;25(3):341-52.

7. Gonzalez-Garcia M, Caballero A, Jaramillo C, Maldonado D, Torres-Duque CA. Prevalence, risk factors and underdiagnosis of asthma and wheezing in adults 40 years and older: a population-based study. J Asthma. 2015;52(8):823-30.

8. Jie $Y$, Isa ZM, Jie $X$, Ju ZL, Ismail NH. Urban vs. rural factors that affect adult asthma[J]. Rev Environ Contam Toxicol. 2013;226:33-63.

9. Jie $Y$, Houjin $H$, Xun $M$, Kebin $L$, Xuesong $Y$, Jie $X$. Relationship between pulmonary function and indoor air pollution from coal combustion among adult residents in an inner-city area of Southwest China. Braz J Med Biol Res. 2014:47(11):982-9.

10. Yu J, Zhang L, Luo Y, Tang Y, Tuo F, Yang J, et al. Indoor environmental factors associated with pulmonary function among adults in an acid rain-plagued city in Southwest China. Wien Klin Wochenschr. 2017:129(7-8):259-68.

11. Fleiss JL. Statistical methods for rates and proportions. Technometrics. 1981; 16(2):326-7.

12. Sakar A, Yorgancioglu A, Dinc G, Yuksel H, Celik P, Dagyildizi L, et al. The prevalence of asthma and allergic symptoms in Manisa, Turkey (a western city from a country bridging Asia and Europe). Asian Pac J Allergy Immunol. 2006;24(1):17-25.

13. Yu J, Zhang L, Luo Y, Tang Y, Tuo F, Yang J, et al. Indoor environmental factors and occurrence of lung function decline in adult residents in summer in Southwest China. Iran J Public Health. 2016;45(11):1436-45.

14. Ait Bamai Y, Shibata E, Saito I, Araki A, Kanazawa A, Morimoto K, et al. Exposure to house dust phthalates in relation to asthma and allergies in both children and adults. Sci Total Environ. 2014;485-486:153.

15. Fu QL, Du Y, Xu G, Zhang H, Cheng L, Wang YJ, et al. Prevalence and occupational and environmental risk factors of self-reported asthma: evidence from a cross-sectional survey in seven Chinese cities. Int J Environ Res Public Health. 2016;13(11):1084-163.

16. Kim KH, Jahan SA, Kabir E. A review on human health perspective of air pollution with respect to allergies and asthma. Environ Int. 2013;59(3):41-52.

17. Kanchongkittiphon W, Mendell MJ, Gaffin JM, Wang G, Phipatanakul W. Indoor environmental exposures and exacerbation of asthma: an update to the 2000 review by the Institute of Medicine. Environ Health Perspect. 2015;123(1):6-20.

18. Pope D, Diaz E, Smith-Sivertsen T, Lie RT, Bakke P, Balmes JR, et al. Exposure to household air pollution from wood combustion and association with respiratory symptoms and lung function in nonsmoking women: results from the RESPIRE trial, Guatemala. Environ Health Perspect. 2015;123(4):285-92.

\section{Publisher's Note}

Springer Nature remains neutral with regard to jurisdictional claims in published maps and institutional affiliations.

\section{Consent for publication}

Not applicable.

\section{Competing interests}

The authors declare that they have no competing interest. 